\title{
Análise computacional da compactação da cromatina de espermatozoides de galo
}

\author{
[Computational analysis of chromatin condensation of rooster spermatozoa] \\ A.C.N. Rodrigues ${ }^{1}$, J.V. Rocha ${ }^{2}$, M.E. Beletti ${ }^{3 *}$ \\ ${ }^{1}$ Faculdade de Medicina Veterinária - Universidade de Uberaba - UNIUBE, Uberaba, MG \\ ${ }^{2}$ Faculdade de Medicina Veterinária - Universidade Federal de Uberlândia - UFU, Uberlândia, MG \\ ${ }^{3}$ Instituto de Ciências Biomédicas - Universidade Federal de Uberlândia - UFU \\ Av. Pará, 1720 \\ 38400-902 - Uberlândia, MG
}

\begin{abstract}
RESUMO
Testaram-se variantes metodológicas utilizando azul de toluidina (AT), até se estabelecer um protocolo confiável para a avaliação computacional da compactação da cromatina em espermatozoides de galo. Para tal, foram utilizados sêmen de 10 galos com 35 semanas de idade e sêmen de 10 galos com 60 semanas de idade. O melhor método foi o de hidrólise com ácido clorídrico $1 \mathrm{~N}$ por 10 minutos, coloração em cubeta com AT $0,025 \%, \mathrm{pH} 4,0$, por 20 minutos, desidratação em álcool, diafanização em xilol e montagem com bálsamo do Canadá. Todas as amostras de sêmen foram submetidas a este protocolo e posteriormente avaliadas por análise de imagem computacional, em que foram feitas mensurações da área, comprimento, largura, perímetro, homogeneidade da compactação da cromatina dentro de cada cabeça e intensidade de compactação da cromatina. Os espermatozoides de galos velhos apresentaram mais alterações na cromatina que os de galos jovens. Os galos jovens apresentaram cabeça dos espermatozoides maior que os galos mais velhos. A análise computacional da compactação da cromatina mostrou-se um método menos subjetivo e mais preciso que a avaliação visual das cabeças dos espermatozoides.
\end{abstract}

Palavras-chave: galo, azul de toluidina, condensação de DNA, fertilidade, análise de imagem, morfometria

\begin{abstract}
The methodological variants using toluidina blue (AT) to establish a trustworthy protocol for the computational analysis of chromatin condensation of rooster spermatozoa were studied. Twenty semen samples were used: ten from 35-week-old roosters and ten from 60-week-old roosters. Different methods of denaturation and staining were tested. The best method was hydrolysis with $1 \mathrm{~N} \mathrm{HCl} \mathrm{for} 10$ minutes, staining in bucket with $0.025 \%$ AT, pH 4.0, for 20 minutes, dehydration in alcohol, clearing in xylol, and mounted with Canada balsam. All the semen samples were submitted to this protocol and later evaluated by computational image analysis. Area, length, width, perimeter, and chromatin compaction homogeneity of head spermatozoa were measured. The sperm of older roosters presented more chromatin changes than the ones of younger ones. The spermatozoa of younger roosters presented bigger heads than the ones of older roosters. The computational analysis of chromatin compaction showed to be less subjective and more precise than the visual evaluation for identification of chromatin alterations of rooster spermatozoa.
\end{abstract}

Keywords: fowl, toluidine blue, DNA condensation, fertility, image analysis, morphometry

Recebido em 12 de janeiro de 2009

Aceito em 16 de novembro de 2009

* Autor para correspondência (corresponding author)

E-mail: mebeletti@ufu.br 


\section{INTRODUÇÃO}

Em aves, devido à queda da fertilidade do lote observada com o passar do tempo, a reposição de parte dos machos é um recurso utilizado para melhorar a fertilização. Por isso, a avaliação da fertilidade dos machos é de grande importância, assim como a busca por métodos mais precisos. As técnicas para diagnóstico de fertilidade em galos são pouco exploradas. Métodos clássicos utilizados para exames andrológicos em outras espécies e diretamente relacionados com o espermatozóide, como motilidade, concentração, vigor e morfologia espermática, também são usados para a avaliação da fertilidade dos galos.

As alterações morfológicas nos espermatozoides de galos dividem-se em defeitos de cabeça e de peça intermediária. Porém essas práticas de rotina não têm sido eficientes na identificação de alterações espermáticas que podem levar à subfertilidade, como alterações na cromatina dos espermatozoides (Soares e Beletti, 2006a).

A condensação do material nuclear é um importante evento da diferenciação nuclear durante a espermatogênese. Estudos mostram que a permanência de histonas somáticas ou ocorrência de anormalidades nas protaminas podem levar à formação de distúrbios de condensação da cromatina dos espermatozoides que se torna frouxa, o que leva a consequências sobre a fertilidade (Evenson et al., 1980; Beletti e Mello, 2004). No caso das aves, a protamina, presente no núcleo da célula espermática, é conhecida como galline (Nakano et al., 1989; Soares e Beletti, 2006b).

Evenson et al. (2002) preconizam que fatores metacromáticos, como os proporcionados pelo alaranjado de acridina (AA) e o azul de toluidina (AT), podem ser utilizados na avaliação da integridade cromatínica do espermatozoide humano e de outras espécies animais, pois os parâmetros clássicos de qualidade espermática não estão bem correlacionados aos quadros de infertilidade e subfertilidade.

Mello (1982) desenvolveu um método para avaliação da cromatina com o uso do AT, um corante catiônico que exibe fenômeno metacromático. A ligação de moléculas do corante azul de toluidina ( $\mathrm{pH} 4,0)$ aos grupos fosfatos ionizados do DNA é importante para avaliação de alterações na cromatina espermática. Este pH de 4,0 garante que outros sítios (ânions) não sejam ionizados. Os espermatozoides normais se corariam em verde, mas aqueles com anomalias no complexo DNAproteína se corariam em violeta. Isto ocorre porque em cromatina normal de espermatozoides, a maioria dos grupos fosfatos está bloqueada por protaminas e, consequentemente, poucas moléculas do corante se ligariam ao DNA, resultando em uma coloração de verde a azul claro. Já para espermatozoides com cromatina pouco compactada, haveria mais ligações com as moléculas do corante, resultando numa coloração de azul escuro a magenta. Porém, somente um alto grau de alteração cromatínica seria identificado por esse método. A sensibilidade desse processo pode ser aumentada pela hidrólise antes da coloração, ou seja, de acordo com o seguinte protocolo: tratamento ácido $(\mathrm{HCl} 4 \mathrm{~N}$ a $25{ }^{\circ} \mathrm{C}, 15$ a 20min) seguido de coloração com azul de toluidina ( $\mathrm{pH} 4,0)$. Espermatozoides normais, que são caracterizados por cromatina altamente compactada, seriam pouco afetados pela hidrólise e, consequentemente, corariam-se em azul claro. Cromatina espermática com baixo grau de alterações poderia ter as protaminas parcialmente extraídas, promovendo ligações das moléculas do corante com os grupos fosfatos do DNA. Deste modo, a sensibilidade do método para identificar anormalidades na cromatina espermática é aumentada.

A detecção de anomalias na cromatina dos espermatozoides em aves tem sido negligenciada. Soares e Beletti (2006a) compararam as alterações morfológicas e de compactação de cromatina com a fertilidade de dois lotes de galos. Eles observaram que, no lote com os galos mais férteis, foi encontrado maior número de espermatozoides com alterações morfológicas, enquanto no lote com menor fertilidade foi encontrado um maior número de alterações na compactação da cromatina, mostrando a importância desta característica na fertilidade dos galos.

A maioria das técnicas usadas para avaliação do sêmen é realizada pela análise visual do examinador, a qual possui certo grau de subjetividade. Na tentativa de se diminuir a subjetividade, as falhas do examinador e aumentar a repetibilidade entre examinadores, 
vem sendo proposto o uso de análise de imagem por computador para a avaliação da motilidade $\mathrm{e}$ da morfologia dos espermatozoides (Beletti et al., 2005b). Outra aplicação para análise de imagem é a caracterização da cromatina de espermatozoides corada com azul de toluidina, que vem sendo concomitantemente usada com a análise morfométrica (Beletti et al., 2005a). Recentemente, o grupo de pesquisa "Cybernetic Vision" do Instituto de Física de São Carlos da USP, em colaboração com Instituto de Ciências Biomédicas da UFU, criaram programas em ambiente "Scilab", para análise morfológica de espermatozoides, independente da espécie (Beletti e Costa, 2003; Beletti et al., 2005b, c). Esses programas avaliam detalhadamente a morfologia da cabeça e estabilidade da cromatina, utilizando esfregaços de sêmen corados com azul de toluidina. Está demonstrado que esses programas identificam alterações morfológicas e de cromatina em sêmen de mamífero, não percebidas pela análise visual do espermograma de rotina (Beletti e Costa, 2003; Beletti et al., 2005a, b, c).

Soares e Beletti (2006a) realizaram estudos preliminares com sêmen de galo corados com AT e análise visual em microscópio de luz e, apesar de não conseguirem desenvolver um protocolo de avaliação confiável, verificaram alta correlação entre cromatina frouxa e baixa fertilidade.

O objetivo deste trabalho foi testar a análise computacional da compactação da cromatina de espermatozoides de galo, utilizando coloração com azul de toluidina e rotinas de análise de imagem desenvolvidas em ambiente de programação Scilab.

\section{MATERIAL E MÉTODOS}

Foram utilizadas 20 amostras de sêmen de galo de duas diferentes idades, coletadas por massagem cloacal, de acordo com a técnica descrita por Wilson (1988). Dez amostras foram coletadas de aves pertencentes a um lote com 35 semanas de idade, peso médio de $4,9 \mathrm{~kg}$ e taxa de fertilidade de 99,4\% (galos novos). As demais amostras foram coletadas de aves pertencentes a um lote com 60 semanas de idade, peso médio de $5,3 \mathrm{~kg}$ e taxa de fertilidade de 96,4\% (galos velhos). Para conservação das amostras, foi colocada uma gota de sêmen em $2 \mathrm{ml}$ de formol citrato (Rodenas et al., 2005; Soares e Beletti, 2006a)

Em seguida, foram testadas variantes metodológicas utilizando colorações com AT com diferentes métodos de desnaturação e coloração. Foram testadas desnaturação précoloração com ácido clorídrico $4 \mathrm{~N}, 1 \mathrm{~N}$ e $0,5 \mathrm{~N}$ por $5,10,15$ e 20 minutos e desnaturação térmica a $60^{\circ} \mathrm{C}$ por 1,5 e 10 minutos, bem como coloração sem prévia desnaturação. Como variantes de coloração, foram testadas soluções de azul de toluidina $0,025 \%$ em $\mathrm{pH} 3,4$ e 5 , utilizando-se uma gota entre lâmina e lamínula com observação após três minutos ou coloração em cubetas por 20 minutos com posterior desidratação em série de concentrações crescentes de álcool, diafanização com xilol e montagem com bálsamo do Canadá. Portanto, foram testadas 96 variantes metodológicas (16 variantes de desnaturação e seis de coloração) em todas as amostras.

A escolha do melhor protocolo de coloração para a visualização das alterações na compactação do DNA dos espermatozoides foi feita pela observação das lâminas em microscopia de luz, sendo escolhido o método em que mais facilmente observaram-se espermatozoides com diferentes intensidades de coloração.

Após a escolha do melhor protocolo de coloração, os esfregaços submetidos ao método escolhido foram novamente visualizados, e imagens foram capturadas com o intuito de passarem pela análise computacional.

Para a análise computacional, imagens digitais foram capturadas em microscópio binocular Olympus BX40 com objetiva de 100x (imersão), acoplado a câmera Olympus OLY-200, ligada a um computador PC por meio de placa digitalizadora Data Translation 3153. Deslocando-se a lâmina em ziguezague, foram capturadas imagens de forma aleatória em toda a extensão da lâmina. Posteriormente, estas imagens foram trabalhadas no programa Jasc Paint Shop Pro $8 \AA$, no qual eram primeiramente passadas para tons de cinza. Em seguida, as cabeças dos espermatozoides que não possuíam sobreposição de imagem foram cortadas e coladas em fundo branco, processo este denominado de segmentação. Foram 
segmentadas 50 cabeças por animal para serem avaliadas individualmente.

As cabeças dos espermatozoides foram analisadas em programa desenvolvido em ambiente de programação SCILAB no qual foram avaliados: área, comprimento, largura, perímetro (Beletti et al., 2005b), homogeneidade da coloração da cabeça (CV) e diferença percentual do valor médio dos pixels que compõem a cabeça em relação ao valor médio dos pixels de cabeças-padrão (Dif. \%). Para se ter uma referência da coloração normal da cabeça do espermatozoide, foram selecionadas visualmente em cada esfregaço seis cabeças desses com coloração homogênea e clara. A média dos valores de pixel dessas cabeças foi considerada como o valor de referência da coloração normal dos espermatozoides (cabeças-padrão) (Silva, 2006).

Para avaliar a homogeneidade da coloração da cabeça, foi calculado o coeficiente de variação (CV) dos valores dos pixels que a compõem (Beletti et al., 2005a; Silva, 2006).

Para a análise estatística, foi utilizado teste Kolmogorov-Smirnov para verificar se os dados possuíam distribuição normal. Uma vez confirmada a normalidade dos dados, utilizou-se o teste $\mathrm{t}$ para comparação entre médias com $\mathrm{P} \leq 0,05$. Também foram calculados os coeficientes de correlação de Pearson entre as variáveis referentes ao tamanho da cabeça (área, perímetro, largura e comprimento) e à compactação de cromatina (coeficiente de variação e diferença percentual).

\section{RESULTADOS E DISCUSSÃO}

O protocolo de fixação utilizando uma gota de sêmen em $2 \mathrm{ml}$ de formol citrato apresentou bons resultados. Soares e Beletti (2006a) descreveram que a fixação dos espermatozoides em lâminas faz com que sua cabeça helicoidal sofra algumas fraturas, alterando o acesso das moléculas de corante, fazendo com que todos os espermatozoides sejam corados como se possuíssem alterações cromatínicas, por isso foi utilizado formol citrato (Rodenas et al., 2005).

Para a determinação do protocolo de coloração, procurou-se estabelecer inicialmente um protocolo de desnaturação da cromatina para a posterior coloração com AT. O melhor método de desnaturação foi a hidrólise com ácido clorídrico $1 \mathrm{~N}$ por 10 minutos, e a melhor coloração foi a realizada em cubeta com azul de toluidina $0,025 \%, \mathrm{pH} 4,0$, por 20 minutos, e posterior desidratação em séries de concentração crescentes de álcool e diafanização em xilol. Com este protocolo, foi possível diferenciar visualmente os espermatozoides mais bem corados em relação aos outros métodos testados. Por essa razão, este foi o protocolo escolhido para diferenciar computacionalmente os espermatozoides normais daqueles com alteração de cromatina, sendo aplicado a todas as amostras de sêmen dos galos jovens e velhos.

Soares e Beletti (2006a) não conseguiram chegar a um protocolo confiável para a avaliação visual da compactação de cromatina utilizando AT. A principal diferença entre os protocolos utilizados por esses autores e o escolhido para a avaliação computacional neste trabalho é a hidrólise com ácido clorídrico feita antes do início da coloração, que não foi realizada no trabalho citado. Apesar de esses autores afirmarem que os espermatozoides de galo apresentam cromatina mais frouxa que a de outras espécies, dispensando a desnaturação ácida, o protocolo escolhido como o mais eficiente no presente trabalho permitiu a diferenciação visual dos espermatozoides mais bem corados (cromatina alterada), por isso, foi aplicado para a análise computacional das cabeças.

$\mathrm{Na}$ análise morfométrica computacional, a partir dos valores das variáveis de cada uma das 50 cabeças, chegou-se à média de cada animal. Com base nessa foi obtida uma média de cada variável dos galos jovens e dos galos velhos (Tab. 1).

Os coeficientes de correlação entre as variáveis analisadas referentes ao tamanho da cabeça e a compactação de cromatina são mostrados na Tab. 2, na qual não foi possível observar correlação estatisticamente significativa. Portanto, baseado nestes dados, não foi possível fazer qualquer inferência sobre a influência da compactação da cromatina sobre a forma da cabeça dos espermatozoides de galo. Segundo Beletti et al. (2005a), as alterações morfológicas causadas por alterações na estrutura da cromatina deveriam aumentar o tamanho da cabeça do espermatozoide. Neste trabalho, não foi mensurado o volume dos espermatozoides, 
somente a área. Apesar de não serem significativos estatisticamente, os coeficientes de correlação foram negativos, demonstrando uma tendência de os espermatozoides dos animais com maior número de alterações na cromatina serem menores.

Tabela 1. Média das características avaliadas na análise computacional da cabeça dos espermatozoides dos galos jovens e velhos (média \pm desvio-padrão)

\begin{tabular}{lcc}
\hline Variável & Galos novos & Galos velhos \\
\hline Área $\left(\mu \mathrm{m}^{2}\right)$ & $9,9 \pm 1,8 \mathrm{a}$ & $8,8 \pm 1,9 \mathrm{~b}$ \\
Perímetro $(\mu \mathrm{m})$ & $29,1 \pm 3,1 \mathrm{a}$ & $27,7 \pm 3,6 \mathrm{~b}$ \\
Largura $(\mu \mathrm{m})$ & $1,0 \pm 0,15 \mathrm{a}$ & $0,98 \pm 0,15 \mathrm{~b}$ \\
Comprimento $(\mu \mathrm{m})$ & $11,0 \pm 2,4 \mathrm{a}$ & $10,2 \pm 2,2 \mathrm{~b}$ \\
CV & $3,8 \pm 2,9 \mathrm{a}$ & $7,5 \pm 7,8 \mathrm{~b}$ \\
Dif. $\%$ & $1,9 \pm 2,3 \mathrm{a}$ & $5,7 \pm 3,2 \mathrm{~b}$ \\
\hline
\end{tabular}

Letras distintas na mesma linha indicam diferenças estatísticas entre os valores, segundo o teste $\mathrm{t}$ com $\mathrm{P} \leq 0,05$.

Tabela 2. Coeficiente de correlação entre as variáveis avaliadas na análise computacional da compactação da cromatina dos espermatozoides dos galos jovens e velhos

\begin{tabular}{ccccc}
\hline Variável analisada & Área & Perímetro & Largura & Comprimento \\
\hline Dif $\%$ & $-0,118$ & $-0,021$ & $-0,064$ & $-0,075$ \\
CV & $-0,107$ & $-0,002$ & $-0,019$ & $-0,107$ \\
\hline
\end{tabular}

Dif $\%=$ diferença percentual dos valores de pixel das cabeças-padrão.

$\mathrm{CV}=$ coeficiente de variação dos valores de pixel da cabeça.

Nenhum dos coeficientes é estatisticamente significativo para $\mathrm{P} \leq 0,05$.

Os galos novos apresentaram as variáveis de tamanho de cabeça maiores que os galos velhos (Tab. 1). Essa diferença pode ser justificada pela presença de um maior número de alterações morfológicas, independentes das alterações de cromatina nos espermatozoides dos galos jovens, o que também foi observado por Soares e Beletti (2006a) em preparados corados com alaranjado de acridina.

Observou-se maior número de alterações na cromatina (CV e Dif\%) nos animais velhos (Tab. 1), ou seja, estes animais apresentavam espermatozoides com cromatina menos homogênea dentro de uma mesma cabeça (CV) e com menor compactação em relação a cabeças normais (Dif\%). Soares e Beletti (2006a) também observaram que galos velhos $(60$ semanas) apresentam maior número de alterações na compactação cromatínica do que galos jovens, porém não conseguiram uma avaliação confiável de esfregaços corados com azul de toluidina, pois esta foi feita visualmente, de maneira subjetiva. A diferenciação foi realizada em esfregaços corados com alaranjado de acridina. Rocha Júnior e Baião (2001) avaliaram sêmen de galos jovens ( 35 semanas) e velhos (68 semanas) e não encontraram diferença significativa nas características físicas espermáticas (motilidade, vigor e turbilhonamento), mostrando que a queda de fertilidade em galos velhos seria causada por outros fatores. No presente trabalho, fica demonstrado que um dos fatores que poderia estar influenciando a fertilidade de galos mais idosos seria as alterações na compactação da cromatina espermática.

A avaliação computacional de esfregaços de sêmen de galo corados com azul de toluidina permitiu uma avaliação menos subjetiva e mais sensível da compactação da cromatina dos espermatozoides. Vários estudos (Beletti et al., 2004; Beletti et al., 2005a, b) concordam que a avaliação computacional pode encontrar alterações que não seriam percebidas pelas análises tradicionais.

\section{CONCLUSÕES}

A análise computacional da compactação da cromatina de espermatozoides de galo em preparados corados com azul de toluidina é um método de avaliação objetivo. Galos velhos apresentam sêmen com mais alterações na cromatina, tanto na homogeneidade como na 
intensidade de compactação. Não existe correlação significativa entre tamanho da cabeça de espermatozoides de galo e condensação de cromatina, no entanto, a cabeça dos espermatozoides de galos velhos tende a ser maior.

\section{AGRADECIMENTOS}

Os autores agradecem à FAPEMIG e ao CNPq, pelo suporte financeiro e à "Granja Planalto" de Uberlândia, pela doação das amostras de sêmen utilizadas neste trabalho.

\section{REFERÊNCIAS BIBLIOGRÁFICAS}

BELETTI, M.E.; COSTA, L.F. A systematic approach to multi-species sperm morphometrical characterization. Anal. Quant. Cytol. Histol., v.25, p.97-107, 2003.

BELETTI, M.E.; COSTA, L.F.; GUARDIEIRO, M.M. Morphometric features and chromatin condensation abnormalities evaluated by toluidine blue staining in bull spermatozoa. Braz. J. Morphol. Sci., v.22, p.85-90, 2005a.

BELETTI, M.E.; COSTA, L.F.; VIANA, M.P. A comparison of morphometric characteristics of sperm from fertile Bos taurus and Bos indicus bulls in Brazil. Anim. Reprod. Sci., v.85, p.105$116,2005 b$

BELETTI, M.E.; COSTA, L.F.; VIANA, M.P. A computational approach to the characterization of bovine sperm chromatin alterations. Biotech. Histochem., v.79, p.17-23, 2004.

BELETTI, M.E.; COSTA, L.F.; VIANA, M.P. A spectral framework for sperm shape characterization. Comput. Biol. Med., v.35, p.463-473, 2005c.

BELETTI, M.E.; MELLO, M.L.S. Comparison between the toluidine blue stain and the Feulgen reaction of rabbit sperm chromatin condensation and their relationship with sperm morphology. Theriogenology, v.62, p.398-402, 2004.

EVENSON, D.P.; DARZYNKIEWICZ，Z.; MELAMED, M.R. Relation of mammalian sperm chromatin heterogeneity to fertily. Science, v.210, p.1131-1133, 1980.
EVENSON, D.P.; LARSON, K.L.; JOST, L.K. Sperm chromatin structure assay is useful for fertility assessment. Methods Cell Sci., v.22, p.169-189, 2002

MELLO, M.L.S. Induced metachromasia in bull spermatozoa. Histochemistry, v.74, p.387-392, 1982.

NAKANO, M.; KASAI, K.; YOSHIDA, K. et al. Conformation of the fowl protamine, galline, and its binding properties to DNA. J. Biochem., v.105, p.133-137, 1989.

ROCHA JÚNIOR, J.M.; BAIÃO, N.C. Características físicas do sêmen de galos de matriz pesada com 35 e 68 semanas de idade. Arq. Bras. Med. Vet. Zootec., v.53, p.683-685, 2001

RODENAS, C.E.O; MURGAS, L.D.S.; MACIEL, M.P. et al. Características seminais de galos alimentados com rações suplementadas com diferentes óleos e níveis de vitamina E. Cienc. Agrotec., v.29, p.160-167, 2005

SILVA, R.T. Correlação da morfometria e da compactação da cromatina de espermatozoides de touro zebuino sobre a taxa de clivagem $e$ formação de blastocistos em programas de produção "in vitro". 2006. 37f. Dissertação (Mestrado em Ciências Veterinárias) Faculdade de Medicina Veterinária, Universidade Federal de Uberlândia, Uberlândia, MG.

SOARES, J.M.; BELETTI, M.E. Avaliação da integridade cromatínica de espermatozoides de galos (Gallus gallus, Linnaeus, 1758) de linhagem pesada em duas idades. Braz. J. Vet. Res. Anim. Sci., v.43, p.543-553, $2006 \mathrm{a}$.

SOARES, J.M.; BELETTI, M.E. Avaliação da morfologia e da compactação cromatínica em espermatozoides de galo (Gallus gallus, Linnaeus, 1758) através de microscopia eletrônica de transmissão. Braz. J. Vet. Res. Anim. Sci., v.43, p.554-560, 2006b.

WILSON, J.L. Métodos para valorar la capacidad reproductiva en gallos reproductores. Avic. Prof., v.6, p.76-81, 1988. 